\title{
Frank Wigglesworth Clarke, a man of vast interests
}

\section{PROF. WILLIAM M WHITE, PHD}

\section{Cornell University}

Presenting Author:wmw4@cornell.edu

Frank Clarke is widely considered one of the fathers of modern geochemistry and with good reason. His interest in the chemistry of the Earth, and indeed the cosmos was broad and his contributions many.

Clark was born in 1847; his mother died within days of his birth and his father, a small-town hardware store owner, sent him to live with his grandparents in Boston where he began a lifelong fascination with minerals. He graduated from Harvard with a degree in chemistry in 1867 . In 1869 he took a position as an assistant in the chemistry department at the new Cornell University, where his interest in geology led him to explore the many gorges and waterfalls in the region and publish a guidebook on them. He subsequently taught chemistry at several colleges over the following decade during which time Clarke became interested in the newly developed astrospectrograph and stellar composition and began his thinking about the chemical evolution of the universe, ideas he would continue to develop over decades that would foreshadow modern cosmology and nucleosynthetic theory. Other important contributions in those years included a compilation of specific gravities, boiling points, and melting points of chemical compounds for the Smithsonian Institution series The Constants of Nature and a chemistry textbook. Clarke served as president of the American Chemical Society in 1901.

Clarke became chief chemist of the U.S. Geological Survey in 1883, a position he held until his retirement in 1924. His publication record over this period is remarkable for its abundance (some 136 papers listed by Google Scholar), diversity, and importance. A broad summary of the chemistry of rocks and natural waters, The Data of Geochemistry is his most cited work. Other works include papers on the heat of formation of water from hydrogen and hydroxyl ions, chemical denudation, systematic studies of the chemistry of mineral classes, a review of atomic theory and papers on the composition of US rivers and lakes, the composition of igneous rocks, the composition of the continental crust, based on 5,197 selected analyses, and the composition of marine invertebrates.

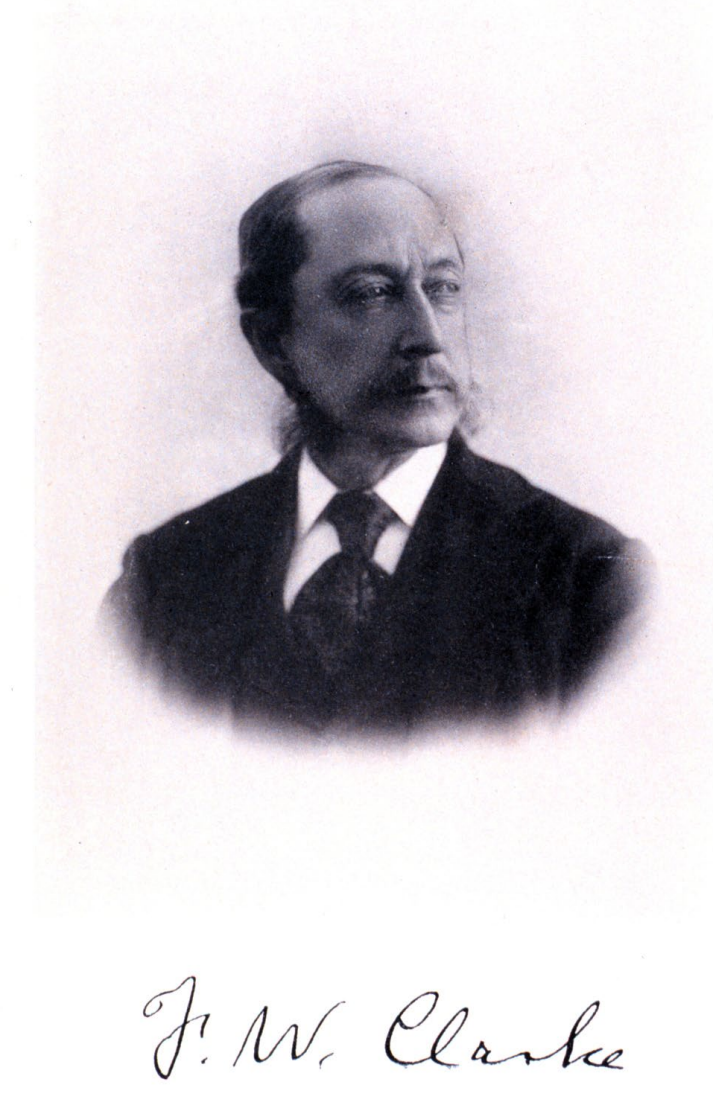

